\title{
Effect of Compatibilizer on Morphology, Thermal and Mechanical Properties of Recycled Carbon Fiber Reinforced Polypropylene Composites
}

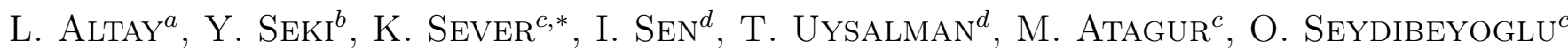 \\ AND M. SARIKANAT ${ }^{a}$ \\ ${ }^{a}$ Ege University, Mechanical Engineering Department, Bornova, Izmir, Turkey \\ ${ }^{b}$ Dokuz Eylul University, Faculty of Science, Buca, Izmir, Turkey \\ ${ }^{c}$ Izmir Katip Celebi University, Faculty of Engineering and Architecture, Cigli, Izmir, Turkey \\ ${ }^{d}$ Izmir Eğitim Sağlık Sanayi Yatırım A.Ş., Turgutlu, Manisa, Turkey
}

\begin{abstract}
Over the last decades, automotive industries have investigated a variety of technological developments and design strategies. The reduction of vehicle weight has been proved to be a particularly effective way to meet automobile performance requirements in the areas of fuel economy and emissions. One major option in the vehicle weight reduction strategy is the use of lightweight materials, namely the carbon fiber reinforced polymers. However, poor adhesion between carbon fibers and polymer matrix could be an important issue for carbon fiber reinforced polymers. In this study, in order to increase interfacial bonding between carbon fibers and the polymer matrix, maleic anhydride grafted polypropylene at different weight contents was used as a compatibilizer for better polymer/fiber interpenetration. Recycled chopped carbon fiber reinforced polypropylene composites with maleic anhydride grafted polypropylene were prepared with high speed thermo kinetic mixing and hot press molding techniques. Thermal properties of the composites were studied by thermal gravimetric analysis and differential scanning calorimety. Morphology of the composites was observed by scanning electron microscopy. The tensile properties of these composites were investigated. Tensile strength values of recycled chopped carbon fiber reinforced polypropylene based composites increased with increasing compatibilizer content.
\end{abstract}

DOI: 10.12693/APhysPolA.134.196

PACS/topics: polypropylene composites, carbon fiber, compatibilizer, mechanical properties

\section{Introduction}

The use of composite materials in many industries, such as automobile, aerospace engineering, sporting goods, transportation and civil industries has increased recently. High strength and stiffness, high toughness, and low weight are the most important characteristics of ideal engineering materials used in these industries.

Polypropylene, one of the widely used thermoplastic polymers due to its excellent properties, is used in combination with reinforcing fibers (e.g., chopped, continuous, mats, fabrics) to obtain polymeric composites with desired properties $[1,2]$.

Short carbon fiber reinforced thermoplastic composites are very attractive because of their ease of fabrication, economy, and superior mechanical properties compared to traditional materials [3]. However, in the case of poor interfacial adhesion between carbon fibers and polypropylene, the increased defect formation could lead to poor mechanical properties of the composites [4].

Polypropylene, due to its non-polar nature, has insufficient solubility in many organic solvents and has limited interactions with other products. Various methods have been studied to improve the interfacial adhesion

*corresponding author; e-mail: kutlay.sever@ikc.edu.tr of composites by modifying polymer matrix, including grafting with hydrophilic functional groups and chemical modifications [5-7].

Incorporation of compatibilizer, such as maleic anhydride-grafted polypropylene (MAPP), is one of the approaches that have been used for improving the adhesion between fibers and polypropylene. The addition of MAPP allows novel and interesting functionalities to be obtained, such as better adhesion or compatibilization. MAPP is a very effective compatibilizer to enhance the interfacial adhesion between carbon fibers and the polymer matrix. Furthermore, improvements in filler/reinforcement and matrix interface play an important role in forming a strong interfacial bond and contribute to the improvements in mechanical properties $[8,9]$.

In this study, in order to improve compatibility between recycled carbon fibers and non-polar polymer matrix of polypropylene, MAPP was used. The objective of this work is to investigate the effects of MAPP content on morphology, thermal and mechanical properties of recycled carbon fibers reinforced polypropylene composites. The thermal, morphological, and mechanical characterizations of composites were performed by thermogravimetric analysis (TGA) and differential scanning calorimetry (DSC), scanning electron microscopy (SEM), and tensile tests, respectively. 


\section{Materials and equipment}

\subsection{Materials}

Polypropylene homopolymer (PP) (Petkim-SOCAR, Turkey) with a density of $0.90 \mathrm{~g} / \mathrm{cm}^{3}$ and a melt flow index of $5 \mathrm{~g} / 10$ min was used as the polymer matrix in this study. Recycled chopped carbon fibers (CF) (ELG Carbon Fiber) with a diameter of $7.5 \mu \mathrm{m}$ and length of $6 \mathrm{~mm}$ were used as the reinforcing material. MAPP purchased from Lushan PR-3C was used as the compatibilizer to fabricate $\mathrm{CF}$ reinforced PP with MAPP composites.

\subsection{Manufacturing of composite materials}

20 wt.\% CF reinforced PP-based composites with 0, 2,4 and 8 wt.\% of MAPP (PP-20CF, PP-20CF-2MAPP, PP-20CF-4MAPP and PP-20CF-8MAPP, respectively) were prepared by using a high speed thermo-kinetic mixer (Gülnar Makina-Turkey). The thermo-kinetic mixer was operated at a shaft speed of $2000 \mathrm{rpm}$ until the material had reached $190^{\circ} \mathrm{C}$. Composite plates $(200 \times 200 \times$ $2 \mathrm{~mm}^{3}$ ) were molded in a compression press, between the hot plates heated to $170^{\circ} \mathrm{C}$ and under pressure of 70-120 bar for $4 \mathrm{~min}$.

\subsection{Characterization techniques}

The mechanical properties of PP, PP-20CF, PP-20CF2MAPP, PP-20CF-4MAPP, and PP-20CF-8MAPP composite specimens were tested at room temperature using a Shimadzu Autograph AG-IS Series universal testing machine equipped with a video extensometer system (SHIMADZU Non-contact VideoExtensometer DVE-101/201) at a crosshead speed of $50 \mathrm{~mm} / \mathrm{min}$ according to ASTM standard D638-10. Tensile strength and modulus were reported for each specimen.

Studies on the morphology of fractured surfaces of CF reinforced PP and CF reinforced PP with MAPP composites after tensile testing were carried out using a scanning electron microscope (Carl Zeiss 300 VP) operated at $3 \mathrm{kV}$.

TGA was performed with thermogravimetric analyzer (TA Instruments SDT Q600). The analyses were carried out under nitrogen atmosphere in the temperature range $30-600^{\circ} \mathrm{C}$ at a heating rate of $10^{\circ} \mathrm{C} / \mathrm{min}$.

DSC measurements were carried out with a TA Instruments DSC Q 2000 calorimeter. The sealed pan was scanned at a heating rate of $10^{\circ} \mathrm{C} / \mathrm{min}$ from 20 to $200^{\circ} \mathrm{C}$ under nitrogen atmosphere.

\section{Results and discussion}

\subsection{Tensile properties}

Figure 1a and $\mathrm{b}$ show the tensile strength and modulus of PP, PP-20CF, PP-20CF-2MAPP, PP-20CF-4MAPP and PP-20CF-8MAPP samples. The results indicate that the tensile strength and modulus of PP increased with addition of 20 wt.\% of CF. When carbon fiber reinforced polypropylene composite is subjected to load,
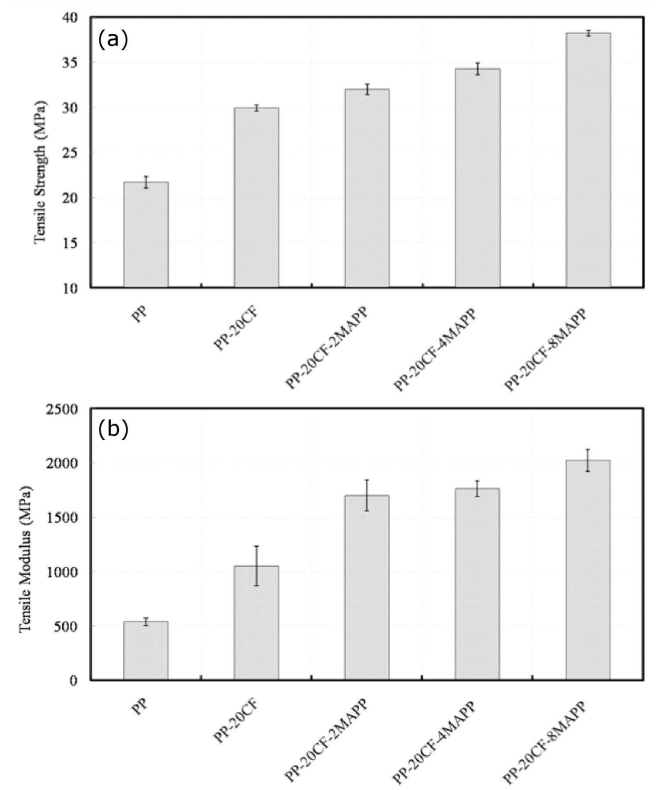

Fig. 1. (a) Tensile strength and (b) modulus of CF reinforced PP composites with MAPP.

carbon fiber acts as a load carrier and stress is being transferred from polymer matrix to fiber [10].

It can be observed that increases in strength and modulus were achieved with addition of 2, 4, 8 wt.\% of MAPP. In the case of MAPP addition, the rate of tensile strength improvement is lower with 2 and $4 \mathrm{wt} . \%$ of MAPP. Tensile strength value of $\mathrm{CF}$ reinforced composite reached the maximum value at $8 \mathrm{wt} . \%$ of MAPP. This amounts to about $28 \%$ improvement compared to PP$20 \mathrm{CF}$ composite. The increase in tensile strength of $\mathrm{CF}$ reinforced PP composites by addition of coupling agent is believed to be due to the improvement in compatibility between the fiber and the polymer matrix $[11,12]$.

\subsection{SEM observation}

Figure 2 shows the SEM images of the fractured surfaces of CF reinforced PP and CF reinforced PP composites with MAPP. Change in interfacial adhesion between PP matrix and carbon fibers when MAPP is used as a compatibilizer can be clearly seen from the SEM micrographs. At 20 wt.\% CF loading without MAPP, a poor adhesion between carbon fibers and PP was observed, as continuous voids close to fibers are visible in Fig. 2a.

However, fiber-matrix bonding (interaction) has been gradually improved with increasing MAPP weight content. Figures $2 \mathrm{~b}, \mathrm{c}$ and $\mathrm{d}$ show the SEM images of the composites containing 2, 4, and 8 wt.\% MAPP, respectively. Detailed investigations of surface morphologies of composites before and after MAPP loading prove the enhanced interfacial adhesion. PP is known to have very poor wettability due to its non-polar hydrocarbon chains which can affect the surface characteristics of the fibers and the matrix [8]. After reaction between MAPP and $\mathrm{PP}$, the adhesive properties and wettability improve proportionally to MAPP content, as seen in Fig. 2b-d. 

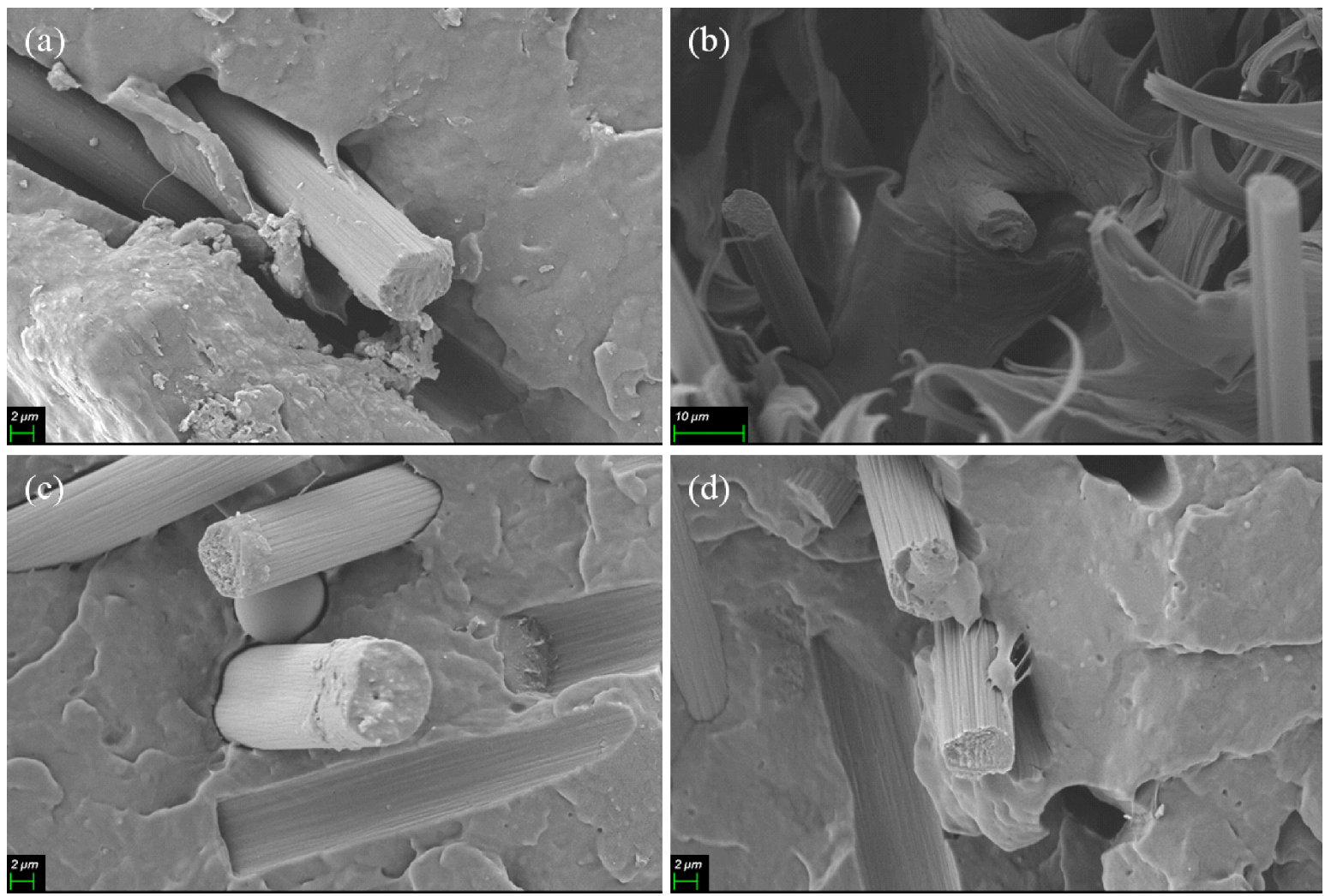

Fig. 2. SEM images of the fractured surfaces of (a) PP-20CF, (b) PP-20CF-2MAPP, (c) PP-20CF-4MAPP, and (d) PP-20CF-8MAPP composites.

\subsection{Thermogravimetric analysis}

Thermograms of PP, PP-20CF and CF reinforced composites with MAPP are shown in Fig. 3. It is seen from Fig. 3 that TG curves of CF reinforced PP composites with and without MAPP are almost the same. MAPP loading has not led to significant variation in the TG curves of CF reinforced PP composites. Maximum degradation temperatures $T_{\max }$ and degraded weight of the samples are given in Table I.

$\mathrm{PP}$ and CF reinforced PP based composites have a single degradation step. The TGA curves of samples demonstrated degraded weights of 97.5, 79.1, 79.2, 79.2 and $79.7 \%$ up to $600^{\circ} \mathrm{C}$ for PP, PP-20CF, PP-20CF-2MAPP, PP-20CF-4MAPP, and PP-20CF-8MAPP, respectively. With the addition of $20 \% \mathrm{CF}$ into PP, the weight loss decreases. $T_{\max }$ values for PP, PP-20CF, PP-20CF2MAPP, PP-20CF-4MAPP, and PP-20CF-8MAPP were obtained to be $461,468,465,464$, and $465^{\circ} \mathrm{C}$, respectively. $T_{\max }$ values are obtained from the first derivative of TGA curves. Addition of carbon fiber into PP increased $T_{\max }$ of PP. This can be attributed to the fact that heat absorption capacity of $\mathrm{CF}$ is higher than that of PP [3]. One can note that thermal stability of CF reinforced PP with MAPP composites is lower than that of PP-20CF but is higher than that of PP. As shown in Table I, MAPP loading has not significantly degraded the thermal stability of CF reinforced PP composites.

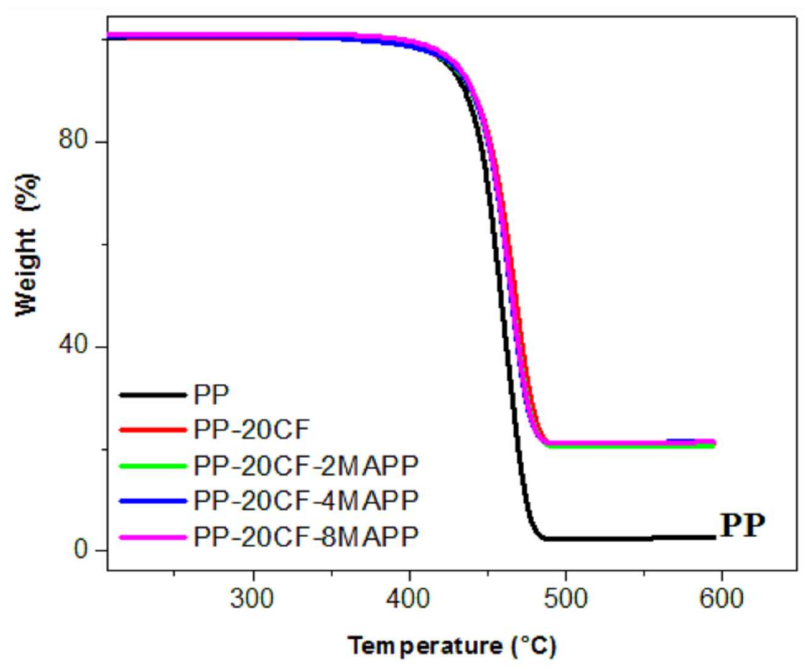

Fig. 3. TG curves of PP, PP-20CF, PP-20CF-2MAPP, PP-20CF-4MAPP, and PP-20CF-8MAPP.

\subsection{DSC analysis}

Table I shows the DSC results of PP and its composites. All composites had a lower melting temperature $T_{\mathrm{m}}$, compared to PP. $T_{\mathrm{m}}$ of PP-20CF composite was $166.2^{\circ} \mathrm{C}$, while the $T_{\mathrm{m}}$ of PP was $167.7^{\circ} \mathrm{C}$. Further, the increased loading level of MAPP had no remarkable effect on the $T_{\mathrm{m}}$ of the composites. 
Thermal properties of PP, PP-20CF, PP-20CF-2MAPP, PP-20CF-4MAPP and PP-20CF-8MAPP

\begin{tabular}{l|c|c|c|c|c|c}
\hline \hline \multicolumn{1}{c|}{ Samples } & $T_{\max }\left[{ }^{\circ} \mathrm{C}\right]$ & $\begin{array}{c}\text { Degraded } \\
\text { weight [\%] }\end{array}$ & $T_{\mathrm{m}}\left[{ }^{\circ} \mathrm{C}\right]$ & $T_{\mathrm{c}}\left[{ }^{\circ} \mathrm{C}\right]$ & $\Delta H_{\mathrm{m}}[\mathrm{J} / \mathrm{g}]$ & $X_{\mathrm{c}}[\%]$ \\
\hline PP & 460.7 & 97.5 & 167.7 & 118.3 & 43 \\
PP-20CF & 468.4 & 79.1 & 166.2 & 125.1 & 89.5 \\
PP-20CF-2MAPP & 464.7 & 79.2 & 166.9 & 124.3 & 82.7 \\
PP-20CF-4MAPP & 464.4 & 79.2 & 167.1 & 124.4 & 82.4 \\
PP-20CF-8MAPP & 464.7 & 79.7 & 165.9 & 125.1 & 88.4 & 59
\end{tabular}

The crystallization temperature $T_{\mathrm{c}}$ of $\mathrm{PP}$ was $118.3^{\circ} \mathrm{C}$, and the addition of $20 \mathrm{wt} . \%$ of CF into PP increased the $T_{\mathrm{c}}$ to $125.1^{\circ} \mathrm{C}$. However, $T_{\mathrm{c}}$ values of the PP-20CF composites did not significantly change with the incorporation of MAPP. Degree of crystallinity $X_{\mathrm{c}}$ was calculated from the melting enthalpy values using Eq. (1):

$$
X_{\mathrm{c}}=\frac{\Delta H_{\mathrm{m}}}{\Delta H_{0} w},
$$

where, $\Delta H_{\mathrm{m}}$ is melting enthalpy of the samples $(\mathrm{J} / \mathrm{g})$, $\Delta H_{0}$ is the melting enthalpy of PP with $100 \%$ crystallinity $(209 \mathrm{~J} / \mathrm{g})[14]$, and $w$ is the weight fraction of polymer in the composite material.

As shown in Table I, the crystallinity of PP was $43 \%$. With the addition of CF into PP, $X_{\mathrm{c}}$ increased to $54 \%$. The addition of MAPP (2 wt.\%) into PP-20CF reduced the $X_{\mathrm{c}}$. However, the higher loading of MAPP (4 and 8 wt.\%) increased the $X_{\mathrm{c}}$. The addition of $\mathrm{CF}$ into the PP has a positive effect on crystallization due to increased interfacial interaction.

\section{Conclusions}

The objective of this work is to investigate the effects of MAPP content on morphology, thermal, and mechanical properties of $\mathrm{CF}$ reinforced $\mathrm{PP}$ composites. Increase in tensile strength and modulus was observed with the addition of 2, 4 and 8 wt.\% of MAPP. Change in morphology of composites indicates that the characteristics of interface between the PP and CF was improved through introduction of MAPP in the system, as a compatibilizer. There has been no significant change in melting temperature of polypropylene when compatibilizer was used. Although $\mathrm{CF}$ addition in $\mathrm{PP}$ increased both the crystallization temperature and the crystallinity of PP, MAPP addition into $\mathrm{CF}$ reinforced $\mathrm{PP}$ composites has not led to significant variation of these properties.

\section{References}

[1] A.S. Luyt, M.D. Dramicanin, Z. Antic, V. Djokovic, Polymer Testing 28, 348 (2009).

[2] Y.W. Leong, M.B. Abu Bakar, Z.A.M. Ishak, A. Ariffin, B. Pukanszky, J. Appl. Polym. Sci. 91, 3315 (2004).

[3] F. Rezaei, R. Yunus, N.A. Ibrahim, E.S. Mahdi, Polym.-Plast. Technol. Engin. 47, 351 (2008).

[4] Z.W. Xu, L. Chen, Y.D. Huang, J.L. Li, X.Q. Wu, X. Li, Y. Jiao, Eur. Polym. J. 44, 494 (2008).

[5] K.H. Wong, D.S. Mohammed, S.J. Pickering, R. Brooks, Compos. Sci. Technol. 72, 835 (2012).

[6] S.J. Park, B.J. Kim, Mater. Sci. Engin. A 408, 269 (2005).

[7] J. Li, Appl. Surf. Sci. 255, 8682 (2009).

[8] H.I. Kim, W. Han, W.K. Choi, S.J. Park, K.H. An, B.J. Kim, Carbon Letters 20, 39 (2016).

[9] H.S. Yang, H.J. Kim, H.J. Park, B.J. Lee, T.S. Hwang, Composite Struct. 77, 45 (2007).

[10] S.Y. Fu, B. Lauke, Compos. Sci. Technol. 56, 1179 (1996).

[11] T.J. Keener, R.K. Stuart, T.K. Brown, Compos. Part A - Appl. Sci. Manuf. 35, 357 (2004).

[12] H.D. Rozman, G.S. Tay, R.N. Kumar, A. Abusamah, H. Ismail, Z.A.M. Ishak, Eur. Polym. J. 37, 1283 (2001).

[13] D.G. Dikobe, A.S. Luyt, eXPRESS Polym. Lett. 4, 729 (2010).

[14] L. Altay, M. Atagur, O. Akyuz, Y. Seki, I. Sen, M. Sarikanat, K. Sever, Polymer Compos. (2017). 